\title{
Untangling the complex kinematic and geochronological history of a crustal-scale shear zone: an example from the Main Central Thrust (Garhwal Himalaya, NW India)
}

\author{
Chiara Montemagni
}

Dipartimento di Scienze dell'Ambiente e della Terra, Università degli Studi di Milano - Bicocca, Milano, Italy. Corresponding author e-mail: chiara.montemagni@unimib.it

Document type: Short note.

Manuscript received 16 April 2021; accepted 07 June 2021; published online 14 June 2021; editorial responsibility and handling by R. Cirrincione.

\section{ABSTRACT}

This contribution focuses on geochronological and kinematic data on the Main Central Thrust zone (MCTz) in the Garhwal Himalaya (NW India). A multidisciplinary approach combining detailed 2D and 3D microstructural observations with a new interpretation key of geochronological data on micas is here applied to reconstruct the polyphase evolution of a crustal-scale shear zone. The Ar Differential Release Plot and the use of X-ray micro-Computed Tomography allow to disentangle misleading Ar/Ar spectra of micas from mylonites and to avoid methodological limitation in vorticity estimates, respectively. This new approach allows to unravel the microstructural and petrological complexities linked to the temporal and kinematic evolution of the MCTz. The obtained data indicate a structurally downward shift of deformation, i.e. towards the foreland, across the MCTz, with an increasing pure shear component mirrored to a progressive rejuvenation of the mica age of structures.

KEYWORDS: Shear zones, Ar/Ar dating, kinematic vorticity, MCT, Himalaya.

\section{INTRODUCTION}

In collisional settings, the kinematic and geochronological analysis of crustal-scale shear zones is of paramount importance to constrain the evolution in space and time of the orogen. One of the most studied and appropriate place on Earth to infer the role of shear zones in the evolution of the orogens is the Himalayan belt (Fig. 1a) for its remarkable exposure and lateral continuity of orogen-scale structures. Moreover, the relatively young age of the Himalayan belt is ideal to observe the orogen at different crustal levels, and thus to extrapolate our understanding both to other collisional belts all around the world and to ancient orogens.

The Himalayan belt consists of tectonic units (Fig. 1a) stacked from the Indian plate and transported towards the south during the collisional stage of orogenesis and subsequent indentation tectonics. All along the orogenic belt, regional scale shear zones accommodated both crustal shortening and orogen parallel extension related to the India-Eurasia convergence since the Middle-Late Eocene (Hodges, 2000).

This contribution focuses on the age and kinematics of the Main Central Thrust zone (MCTz), a km-thick thrust- sense top-to-SW shear zone dipping to the north, cropping out at the base of the Greater Himalayan Sequence (GHS), the crystalline core of the belt. The study area includes Bhagirathi (Fig. 1b) and Alaknanda (Fig. 1c) valleys in the Garhwal region (NW India) where the MCTz is well exposed and bounded by the Vaikrita Thrust at the top (the MCT sensu stricto) and the Munsiari Thrust at the bottom (Fig. 1b-c), two well-recognizable in the field thrust-sense shear zones.

The exact location, the structural evolution and the age of the MCTz are still a matter of debate in the Himalayan literature (e.g. Carosi et al., 2019; Montemagni et al., 2019 and references therein), as several different criteria have been proposed by many authors to define the MCTz (Searle et al., 2008; Martin, 2017; Carosi et al., 2018), resulting as well in ages ranging from $22 \mathrm{Ma}$ to $3 \mathrm{Ma}$ in different areas of the belt. This is related to the different chronometer choice (i.e. K-Ar, ${ }^{40} \mathrm{Ar} /{ }^{39} \mathrm{Ar}$, U-Th-Pb, Rb/Sr, AFT and ZFT) applied to polydeformed and polymetamorphic intensively sheared rocks.

Several contrasting models have been proposed for the exhumation of the GHS (e.g. Montomoli et al., 2013), and the estimated timing of the MCTz and the South Tibetan Detachment System (STDS) is crucial to validate the proposed models: constraining the chronological and structural evolution of the MCTz is therefore of fundamental relevance to unravel the evolution of the Himalayan orogen. Another key parameter in the exhumation models of the GHS is the deformation regime, namely the pure and simple shear components of deformation (Godin et al., 2006; Montomoli et al., 2013; Carosi et al., 2018), which can be expressed by the kinematic vorticity number $\left(\mathrm{W}_{\mathrm{m}}\right)$.

As the $\mathrm{MCTz}$ is a structurally and petrologically complex shear zone, multidisciplinary approaches are needed to effectively get deeper insights into its evolution in time and space. The ${ }^{40} \mathrm{Ar} /{ }^{39} \mathrm{Ar}$ step-heating approach, the most useful for the present study, is a key procedure for unravelling petrological and chemical complexities, because of the recognition of different ages due to different steps of Ar release characterized by different $\mathrm{Cl} / \mathrm{K}$ and $\mathrm{Ca} / \mathrm{K}$ ratios. This method, combined with a new methodological approach first developed in detail during my Ph.D. project, 

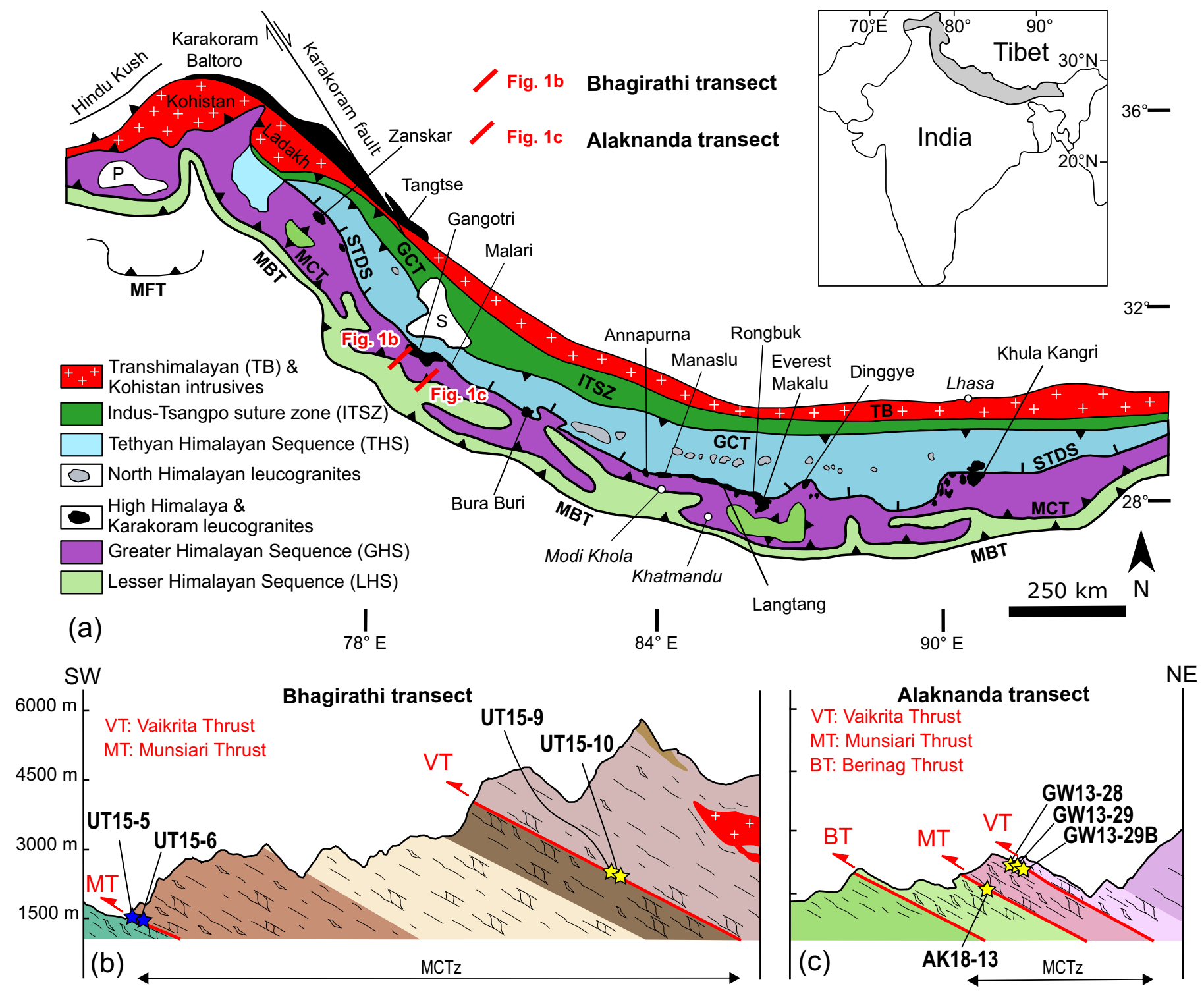

Fig. 1 - (a) Simplified geological map of the Himalaya (modified after Weinberg, 2016). (b) The Bhagirathi transect. (c) Alaknanda transect. Stars show the structural position of the analysed samples by ${ }^{40} \mathrm{Ar} /{ }^{39} \mathrm{Ar}$ (yellow and blue) and for vorticity estimate (blue). Abbreviations: GCT, Great Counter Thrust; STDS, South Tibetan Detachment System; MCT, Main Central Thrust; MBT, Main Boundary Thrust; MFT, Main Frontal Thrust.

has been applied to rocks sampled from the MCTz. This new procedure, named Ar Differential Release Plot (DRP), allows to clearly identify the influence of the co-existence of phyllosilicates on the trend of Ar release during heating steps (Montemagni \& Villa, 2021). This, in turn allows to select the optimal steps corresponding to the degassing of micas sensu stricto, which leads to more reliable age determinations in such metamorphic multi-deformed rocks.

Moreover, a new three-dimensional approach based on the X-ray micro Computed Tomography (micro-CT) analytical method has been developed and applied to study the kinematic of flow within the MCTz using the stable porphyroclasts method. Several methods have been developed to infer $\mathrm{W}_{\mathrm{m}}$, among these stable porphyroclasts method (Passchier, 1987; Wallis et al., 1993) has been widely used to deduce kinematic vorticity in a variety of geological settings (Xypolias et al., 2010 with references; Fossen \& Cavalcante, 2017) but it undergoes limitations in a classical thin section based study. Precisely for this reason a new three-dimensional based approach using the micro-CT has been firstly developed (Montemagni et al., 2020) during my Ph.D. work.

Generally speaking, these methodological approach can play a breakthrough role in unravelling the age of shearing in polydeformed, altered rocks from shear zones, and can be effectively routinely applied in constraining the structural and chronological evolution of a shear zone.

\section{MATERIALS AND METHODS}

Microstructural observations, together with ${ }^{40} \mathrm{Ar} /{ }^{39} \mathrm{Ar}$ geochronology and vorticity estimates, have been performed on field-oriented samples from Alaknanda and Bhagirathi valleys. Samples were cut perpendicular to the main foliation and parallel to lineation, representing the 
XZ plane of the finite strain ellipsoid.

After microstructural observations, which led to the recognition of different textural generation of micas (Montemagni et al., 2019, 2020; Montemagni \& Villa, 2021), and chemical analyses, selected samples (GW1328,29,29B; UT15-5,6,9,10; AK18-13) were sieved and micas, in the fractions $125-250 \mu \mathrm{m}$, were separated and cleaned by protracted handpicking. In order to constrain the shearing activity of Vaikrita and Munsiari Thrust, mica along the main foliation (mica-2) has been selected for dating; mica that texturally overprints the main foliation (mica-3) put a constraint for the cessation of the shearing, which has to be stopped before the crystallization of undeformed micas. Relict mica is only locally preserved (mica-1) and it has not been selected for dating because of its scarcity.

Mica aliquots with different degrees of purity has been intentionally analyzed by handpicking the separate obtained by gravimetric and magnetic techniques.

Samples were irradiated, carefully avoiding $\mathrm{Cd}$ shielding, in the McMaster University reactor (Ontario, Canada) at $30 \mathrm{MWh}$. Standards of McClure Mountain hornblende (MMhb), with an assumed age of $523.98 \pm 0.12$ Ma (Schoene \& Bowring, 2006), were interlayered with the samples. Stepwise heating was performed in a doublevacuum furnace at Dipartimento di Scienze dell'Ambiente e della Terra, Università degli Studi di Milano - Bicocca, whose temperature was kept constant for the duration of each heating step. The full description of the step-heating procedure is reported in Villa et al. (2000) and Bosio et al. (2020).

Kinematic vorticity number has been obtained through stable porphyroclasts method (Fig. 2a) applied to mylonitic orthogneiss of the Munsiari Thrust (Fig. 2b) in the Bhagirathi valley. The method assumes that, in a general shear flow, porphyroclasts are partitioned in a population which do not develop a preferred orientation and in a population which reached a minimum energy position. The cut off of the envelope of data allows to calculate $\mathrm{W}_{\mathrm{m}}$ as it divides the two populations (e.g. Wallis et al., 1993; Jessup et al., 2007).

This method has always been applied in thin section analysis, nevertheless clasts motion is a complex three dimensional issue, as pointed out by several authors (e.g. Iacopini et al., 2011; Li \& Jiang, 2011; Mancktelow, 2013). The use of X-ray micro-CT has been applied to three dimensional study of rocks (Fig. 2c) since '90s (Denison \& Carlson, 1997; Baker et al., 2012; Corti et al., 2019 and references therein) and it is useful to address the study of kinematic vorticity using the stable porphyroclasts method (Montemagni et al., 2020). Micro-CT scans were performed with a BIR Actis 130/150 Desktop Micro-focus CT/DR system at Dipartimento di Scienze dell'Ambiente e della Terra, Università degli Studi di Milano - Bicocca. Method details and analytical procedure is reported in Zanchetta et al. (2011).

\section{RESULTS}

This multidisciplinary approachallows to establishalink between microstructures, kinematic and geochronology, and would be used to disentangle information deriving from structural and petrochronological complex deformed rocks.
In order to assess the kinematic vorticity, 152 (UT155) and 32 (UT15-6) porphyroclasts, with a variable size from $\mathrm{mm}$ to $\mathrm{cm}$-scale, have been analysed from mylonitic orthogneiss from the Munsiari Thrust (Fig. 2b) through $\mathrm{X}$-ray micro-CT scanning. The Rigid Grain Net (RGN) plot by Jessup et al. (2007) has been used, comparing the results with the original plot by Wallis et al. (1993; Fig. 2d,e). Vorticity numbers range between $0.53-0.58$ (UT15-6) and 0.49-0.57 (UT15-5). To validate and compare the 3D micro-CT based approach with a classical thinsection based approach, 30 slices have been randomly selected on the XZ plane, in which 72 porphyroclasts have been measured. Figure $2 \mathrm{~d}$ compares the difference in porphyroclasts population distributions from sample UT15-5 as obtained from 3D micro-CT analyses with the one based on 2D sections: vorticity cannot be defined adopting 2D approach because of clasts with long axes at higher angles with respect to foliation and clasts with the higher B* (sensu Jessup et al., 2007) values are absent. It is clear that using the micro-CT all the clasts in the sample are instead evaluated, discarding those which do not satisfy the requirements of the theory, this cannot be done using classical thin section based analysis.

${ }^{40} \mathrm{Ar} /{ }^{39} \mathrm{Ar}$ step-heating approach on biotite and muscovite is a key procedure to constrain the age of shearing and especially to unravel petrological and chemical complexities (Fig. 3). As Ar/Ar spectra give only partial information especially in such polydeformed and metamorphic rocks, the use of, at least, correlation diagrams is needed (Fig. 3a-d), in which $\mathrm{Ca} / \mathrm{K}$ and $\mathrm{Cl} / \mathrm{K}$ ratios are plotted and selecting the step age with the lowest $\mathrm{Ca}$ and constant $\mathrm{Cl}$ so to take into account the isochemical steps only for the age calculation (Fig. 3d). MCTz samples show remarkable microstructural and chemical complexities, due to the coexistence of several micas generations which, as demonstrated by BSE and $\mathrm{X}$-ray elemental maps, are intimately intergrown at a scale of several tens of microns, therefore preventing a complete purity separation by hand picking.

The age of shearing of Vaikrita Thrust in the Alaknanda has been constrained, through this approach, at $9 \mathrm{Ma}$ (Fig. 3a-d) whereas the shearing has to be ceased before $6 \mathrm{Ma}$, as suggest by microstructures.

But what if neither the spectra nor the correlation diagrams allow to define an age? As exhaustively reported in Montemagni \& Villa (2021), the Bhagirathi MCTz samples required a deeper investigation to disentangle the disturbed and misleading Ar/Ar spectra. To takle this problem (Fig. 3e-h), aliquots with different degrees of purity have been prepared from Vaikrita and Munsiari samples, so to observe their crystal structure collapse in the Ar DRP approach. The Ar DRP diagram shows the degassing temperature of each step in the furnace of the spectrometer $v s$. the release of ${ }^{39} \mathrm{Ar}$ isotope divided by the temperature increase (Fig. $3 \mathrm{~g}$ ). The peaks in the diagram correspond to the crystal structure collapse: in all the analysed samples, chlorite degasses distinctly before muscovite and biotite. The procedure allows quantifying the bias given by fine-grained phyllosilicates and allow discriminating the lattice collapse of micas sensu stricto from that of chlorite. The lattice collapse peaks in DRP correspond to the lowest $\mathrm{Ca} / \mathrm{K}$ and $\mathrm{Cl} / \mathrm{K}$ signature coming from the correlation diagrams (Fig. 3h). 

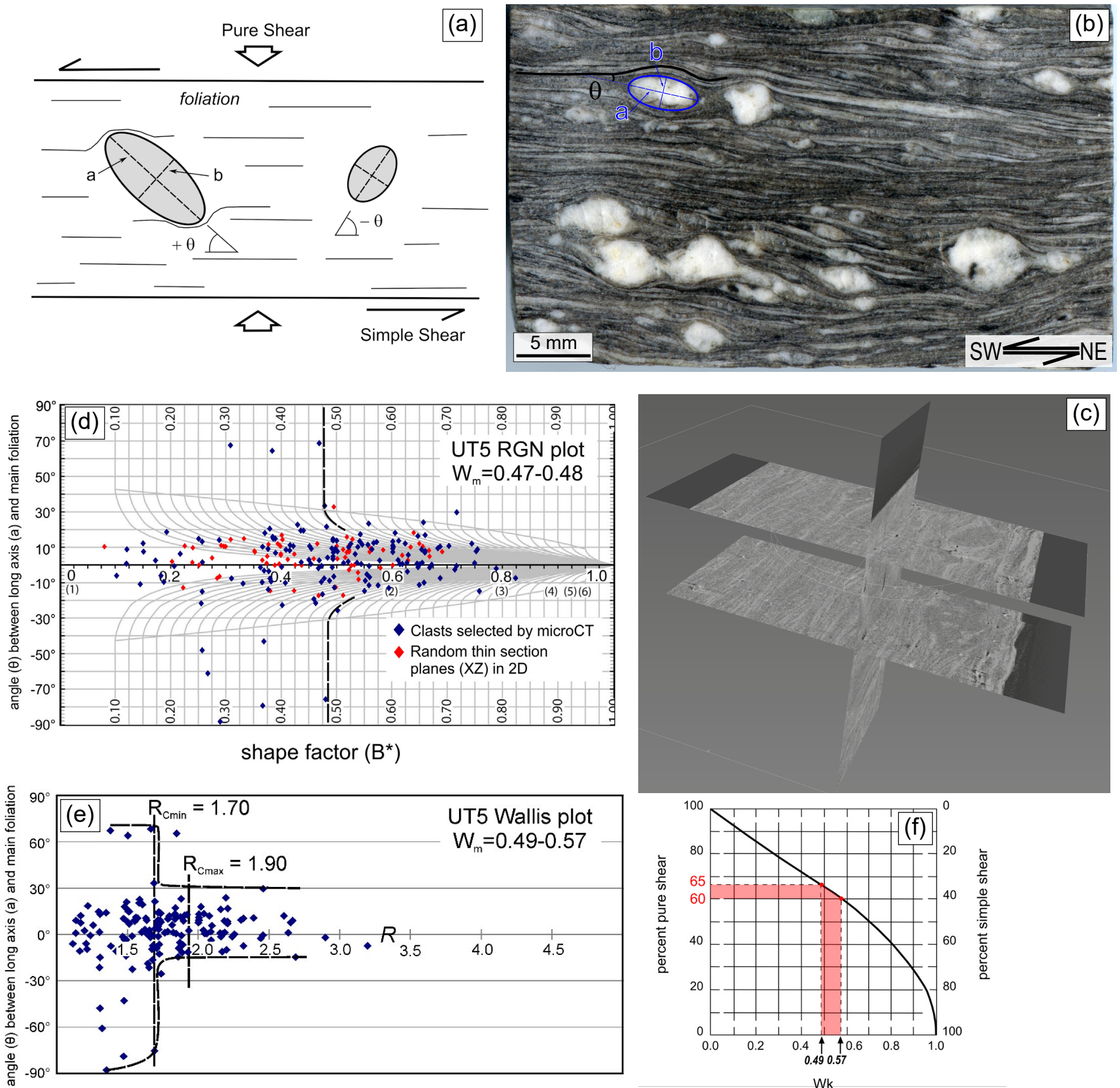

Wk

Fig. 2 - (a) Sketch of the parameters to be measured in stable porphyroclasts method. (b) Hand-sample of mylonitic orthogneiss of Munsiari Thrust. (c) 3D visualization through the software Avizo ${ }^{\mathrm{TM}}$ of the micro-CT scan. Results of the vorticity analyses using the RGN plot (d) of Jessup et al. (2007) and (e) the Wallis plot (Wallis et al., 1993). In (d) the comparison between 2D (red dots) and 3D (blue dots) selected clasts has been shown. (f) Relationship between kinematic vorticity number and associated components of simple and pure shear (Law et al., 2004) for analyzed samples. $\mathrm{Rc}_{\min }$ : minimum value of critical aspect ratio; $\mathrm{Rc}_{\max }$ : maximum value of critical aspect ratio; a: long axis of the clast; b: short axis of the clast; $\theta$ : angle between the axis and the main foliation.

Adopting this approach, the ages of shearing along the Vaikrita and Munsiari thrusts have been constrained at 8.17 and c. $5 \mathrm{Ma}$, respectively. The cessation of shearing along the Vaikrita Thrust has to be occurred around 7 $\mathrm{Ma}$, as suggested by static growth of undeformed micas overprinting the main foliation.

\section{DISCUSSION}

Non-routine multidisciplinary approach have been used to satisfactorily define the kinematic and temporal evolution of the MCTz (Fig. 4). The first and foremost observation is that the application of ${ }^{40} \mathrm{Ar} /{ }^{39} \mathrm{Ar}$ ages of micas from mylonites 
Alaknanda samples approach

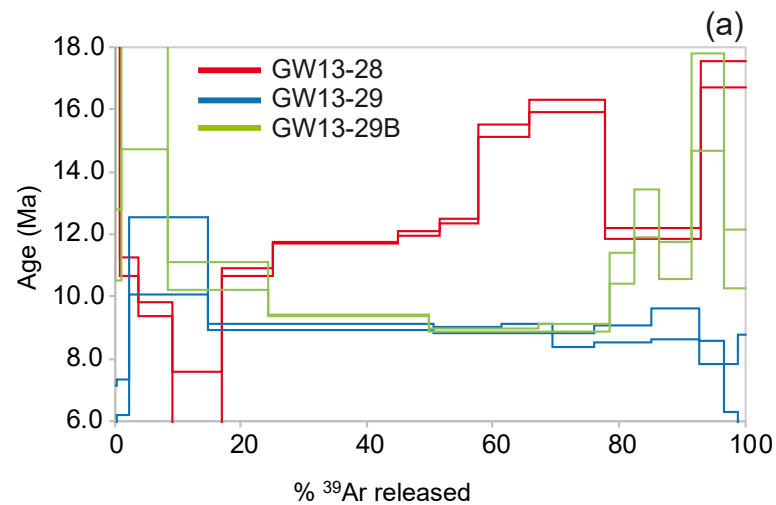

(b)

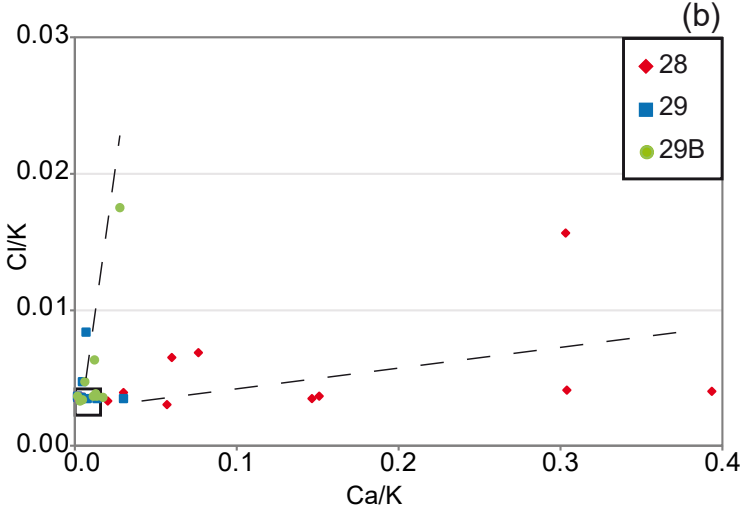

(c)

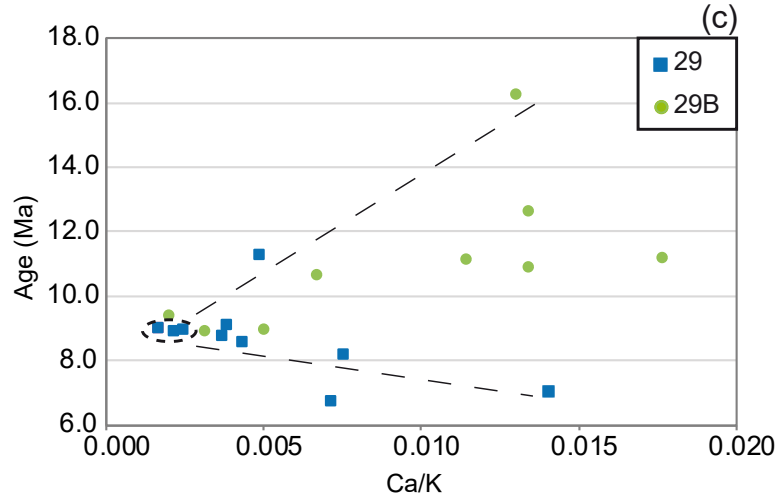

(d)

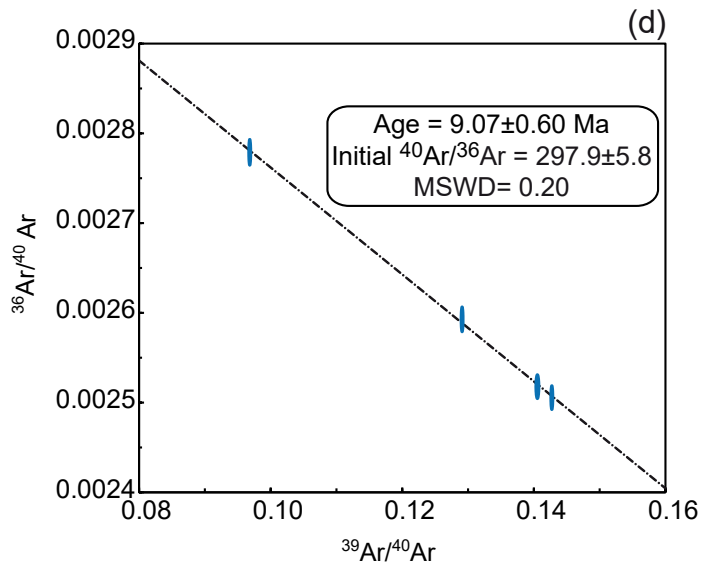

Bhagirathi samples approach

(e)

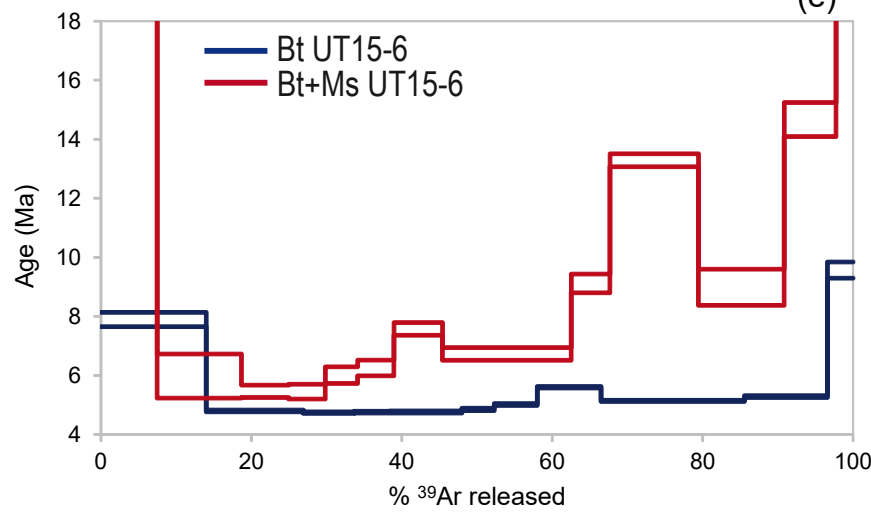

(f)

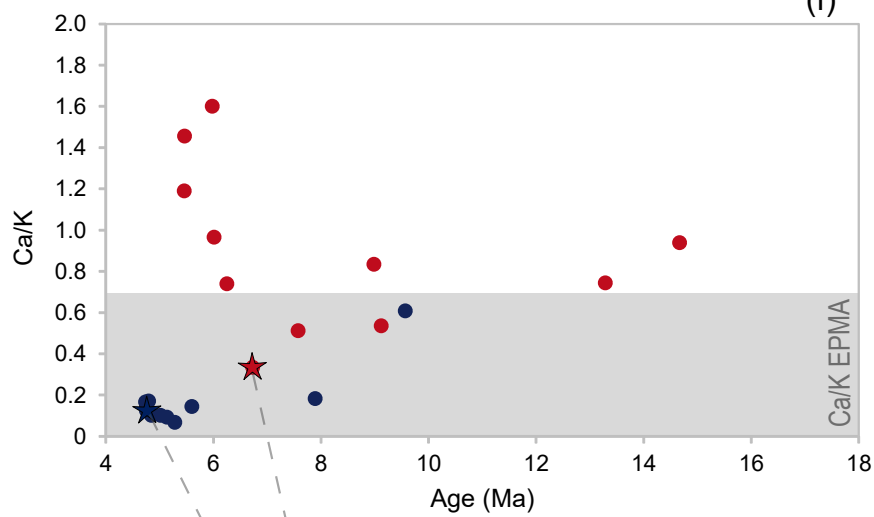

(g)

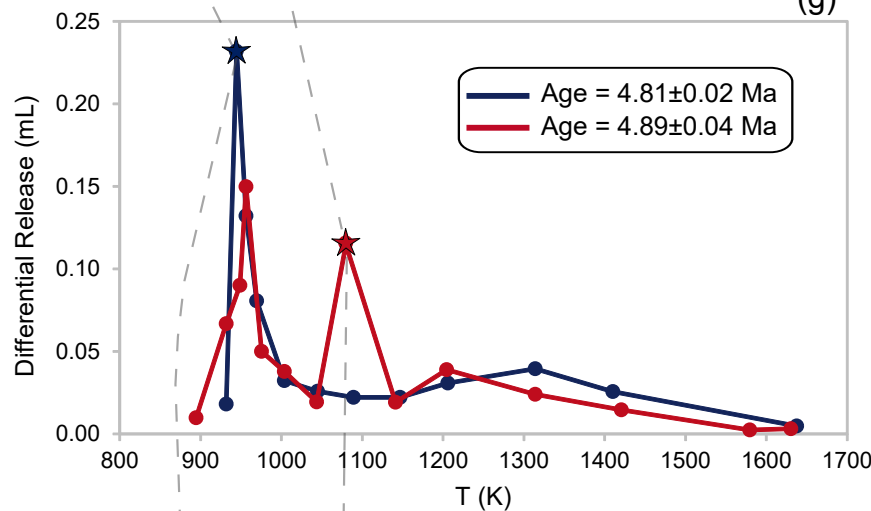

(h)

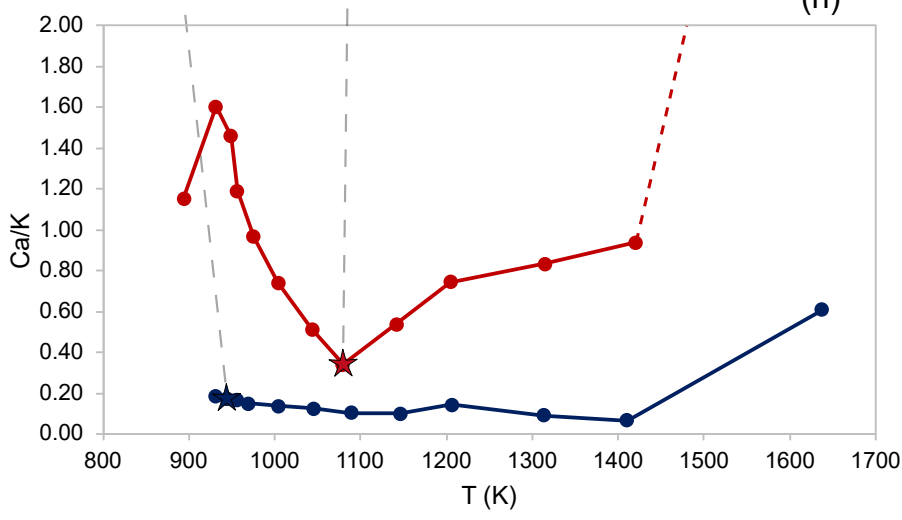

Fig. 3 - Alaknanda (a-d) vs. Bhagirathi (e-h) samples approach to determine ${ }^{40} \mathrm{Ar}{ }^{39} \mathrm{Ar}$ ages. In (b) the inset shows the low $\mathrm{Cl}-$ low $\mathrm{Ca}$ analyses reliable for the age determination, the dashed lines represent trend of low $\mathrm{Ca}$-variable $\mathrm{Cl}$ and variable $\mathrm{Ca}$-low $\mathrm{Cl}$ (the steeper one). In (c) the dotted ellipse identifies the isochemical steps. (d) Isochron obtained with the four isochemical steps of sample GW13-29. In (f) the grey box reports the range of $\mathrm{Ca} / \mathrm{K}$ measured by EMP. The stars highlight the selected step for age calculation. In (h) two points at high temperatures are out of scale as their $\mathrm{Ca} / \mathrm{K}$ ratio is too high and probably $\mathrm{Ca}$ is not derived from micas (the theoretical $\mathrm{Ca} / \mathrm{K}$ value for micas should be equal to zero). 
of the $\mathrm{MCTz}$ have been defined through the DRP and correlation diagrams on both samples from the Bhagirathi valley and samples from the Alaknanda valley. This approach leads straightforwardly to achieve robust age data otherwise almost impossible to obtain through the generally commonly used ${ }^{40} \mathrm{Ar} /{ }^{39} \mathrm{Ar}$-released $v s$. age spectra only.

The kinematic analysis of flow of most of the studied samples from the $\mathrm{MCTz}$ was obtained through a 3D approach, using a X-ray micro-CT scan. X-ray microCT allows to greatly improve the estimate of kinematic vorticity using rigid porphyroclasts method, because of its spatial resolution and the huge number of investigated clasts with respect to traditional thin section-based method. Moreover, the possibility to inspect the third dimension avoids potentially misleading 2D measurements that generate systematic errors in the vorticity evaluation.

In order to get constraints for the exhumation models of the GHS, the deformation regime of the MCTz from west to east (NW India, Nepal and Bhutan) was the subject of several studies (Montemagni et al., 2020 with references). As reviewed in Montemagni et al. (2020), a large pure shear component has been reported along the MCT from India to Bhutan, and the results of stable porphyroclasts analysis on mylonitic orthogneisses from the Munsiari Thrust confirms a dominance of the pure shear component (65-60 $\%, \mathrm{~W}_{\mathrm{m}}=0.49-0.57$; Fig. $2 \mathrm{f}$ ).

The age of shearing from the hinterland towards the foreland of the $\mathrm{MCTz}$ (i.e. from the Vaikrita to the Munsiari thrusts) rejuvenates following this direction (Fig. 4), as ${ }^{40} \mathrm{Ar} /{ }^{39} \mathrm{Ar}$ ages of the main foliation from Vaikrita and Munsiari Thurst shift from c. 8.17 to $4.8 \mathrm{Ma}$ and from 9 to $5.4 \mathrm{Ma}$ in the Bhagirathi and Alaknanda valleys, respectively.

The progressive deformation recorded within the MCTz (Fig. 4) appears to follow the structural evolution of the whole belt, suggesting an inter- and intra-shear zone evolution towards the foreland. One could speculate here that in the framework of models proposed for shear zones evolution (Hull, 1988; Fossen, 2010), the MCTz could have followed a thickening evolution in space. The correlation between ages and structural features (Fig. 4) suggests a progressive migration of deformation towards the base of the MCTz, with the upper shear zone (i.e. the Vaikrita Thrust) becoming inactive (as testified by mica3 microstructures) while deformation shifts and focuses in the basal shear zone (i.e. the Munsiari Thrust). Thus, this mechanism leads to a thickening of the shear zone as a whole (i.e. the MCTz). The foreland-sense migration of deformation is likely linked to strain hardening with temperature decreasing during exhumation. With respect to the symmetric models of shear zones evolution proposed by Fossen (2010), the MCTz evolved asymmetrically, largely following the in-sequence evolution observed at the orogen scale, related to the high subduction velocity of India beneath the Eurasia margin. On these bases, the MCTz should be considered as a shear zone with deformation progressing in sequence from the structurally upper boundary (i.e. Vaikrita Thrust) to the lower, younger one (i.e. Munsiari Thrust), with mylonites occurring seamlessly between the two main structures (Fig. 4).

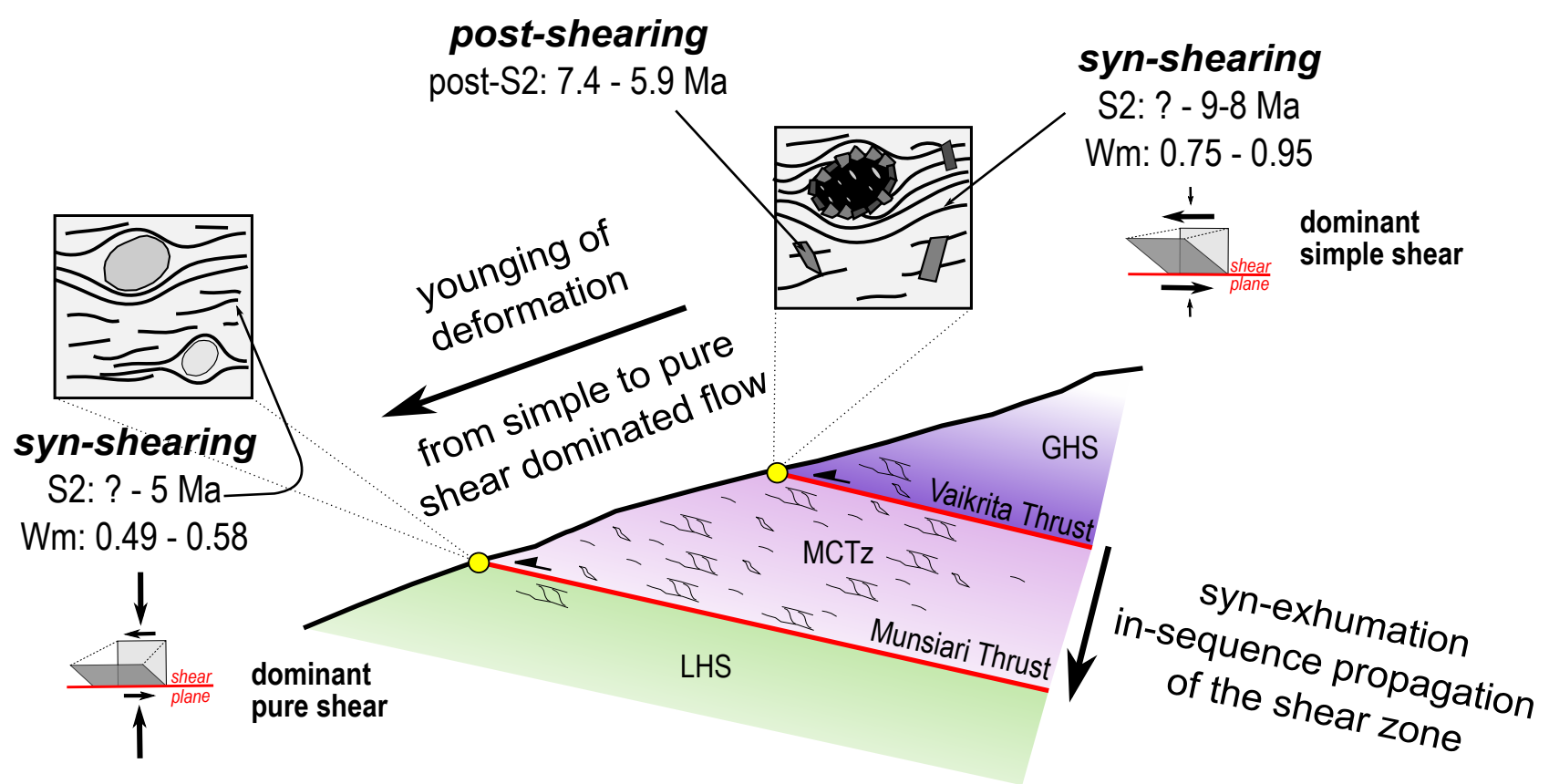

NOT TO SCALE

Fig. 4 - Evolution of the MCTz obtained combining geochronological and kinematic data from Alaknanda and Bha.girathi transects. 


\section{CONCLUSIONS}

A combined multidisciplinary approach, firstly based on detailed microstructural observation such the one presented in this study is recommended to correctly interpret complex kinematic and geochronological data related to crustal-scale shear zones. The new approaches presented above, namely the Ar DRP and micro-CT scan for vorticity estimates, are quite effective for a rigorous approach to unravel the microstructural and petrological complexities linked to the temporal and kinematic evolution of the Main Central Thrust zone of the Himalaya orogenic belt. The main points covered in such study are:

1. Estimate the ages pertaining to the activity of shear zones is facilitated by the simultaneous use of $\mathrm{Ca} / \mathrm{Cl} / \mathrm{K}$ signatures with DRP, which identify the age steps to be correctly used in age determination.

2. Estimate the kinematic vorticity using rigid porphyroclasts method through the micro-CT scan is a state of the art strategy to avoid the $2 \mathrm{D}$ approach limitations.

3. Kinematic vorticity data suggest that the exhumation of the GHS has been driven by a decrease of simple shear during exhumation, coherent with all published data along the belt from west to east.

4. In the Garhwal Himalaya, results support an insequence shearing from c. 9-8 to c. 5-4 Ma from Vaikrita to Munsiari Thrust.

5. The MCTz should be considered as a single shear zone evolving in time and space, following the insequence orogen scale evolution, with the variation in deformation regime towards higher pure shear values combined with a younging of mica ages.

\section{ACKNOWLEDGMENTS}

I am fully grateful to Prof. Igor M. Villa, Prof. Chiara Montomoli Prof. Rodolfo Carosi and Dr. Salvatore Iaccarino who supervised and supported my research in many different ways. This work is part of the PhD grant in "Chemical, Geological and Environmental Sciences", Università degli Studi di Milano - Bicocca.

E. Fazio and one anonymous reviewer are warmly thanked for their reviews, which improved the quality of the paper. The Editor Matteo Berti is thanked for the handling of the paper.

\section{REFERENCES}

Baker D.R., Mancini L., Polacci M., Higgins M.D., Gualda G.A.R., Hill R.J. \& Rivers M.L. (2012) - An introduction to the application of X-ray microtomography to the three-dimensional study of igneous rocks. Lithos, 148, 262-276.

Bosio G., Malinverno E., Villa I.M., Di Celma C., Gariboldi K., Gioncada A., Barberini,V., Urbina M. \& Bianucci G. (2020) - Tephrochronology and chronostratigraphy of the Miocene Chilcatay and Pisco formations (East Pisco Basin, Peru). Newsl. Stratigr., 53, 213-247.

Carosi R., Montomoli C. \& Iaccarino S. (2018) - 20 years of geological mapping of the metamorphic core across Central and Eastern Himalayas. Earth-Sci. Rev., 177, 124-138.

Carosi R., Montomoli C., Iaccarino S. \& Visonà D. (2019) - Structural evolution, metamorphism and melting in the Greater Himalayan Sequence in central-western Nepal. Geol. Soc. London Spec. Publ., 483, 305-323.

Corti L., Zucali M., Visalli R., Mancini L. \& Sayab M. (2019) Integrating X-ray computed tomography with chemical imaging to quantify mineral re-crystallization from granulite to eclogite metamorphism in the Western Italian Alps (Sesia-Lanzo Zone). Front. Earth Sci., 7, 327.
Denison C. \& Carlson W.D. (1997) - Three-dimensional quantitative textural analysis of metamorphic rocks using high-resolution computed X-ray tomography: Part II. Application to natural samples. J. Metamorph. Geol., 15, 45-57.

Fossen H. \& Cavalcante G.C.G. (2017) - Shear zones: a review. Earth Sci. Rev., 171, 434-455.

Fossen H. (2010) - Structural geology. Cambridge University Press.

Godin L., Grujic D., Law R.D. \& Searle M.P. (2006) - Channel flow, ductile extrusion and exhumation in continental collision zones: an introduction. In: Channel flow, ductile extrusion and exhumation in continental collision zones (Law, R.D., Searle, M.P. and Godin, L., eds). Geol. Soc. London Spec. Publ., 268, 1-23.

Hodges K.V. (2000) - Tectonics of the Himalaya and southern Tibet from two perspectives. Geol. Soc. Am. Bull., 112, 324-350.

Hull J. (1988). Thickness-displacement relationships for deformation zones. J. Struct. Geol., 10(4), 431-435.

Iacopini D., Frassi C., Carosi R. \& Montomoli C. (2011) - Biases in three-dimensional vorticity analysis using porphyroclast system: limits and application to natural examples. Geol. Soc. London Spec. Publ., 360, 301-318.

Jessup M.J., Law R.D. \& Frassi C. (2007) - The rigid grain net (RGN): an alternative method for estimating mean kinematic vorticity number $\left(\mathrm{W}_{\mathrm{m}}\right)$. J. Struct. Geol., 29, 411-421.

Law R.D., Searle M.P. \& Simpson R.L. (2004) - Strain, deformation temperatures and vorticity of flow at the top of the Greater Himalayan Slab, Everest Massif, Tibet. J. Geol. Soc., 161, 305 320.

Li C. \& Jiang D. (2011) - A critique of vorticity analysis using rigid clasts. J. Struct. Geol., 33, 203-219.

Mancktelow N.S. (2013) - Behaviour of an isolated rimmed elliptical inclusion in 2D slow incompressible viscous flow. J. Struct. Geol., 46, 235-254.

Martin A.J. (2017) - A review of definitions of the Himalayan Main Central Thrust. Int. J. Earth Sci., 106, 2131-2145.

Montemagni C. \& Villa I.M. (2021) - Geochronology of Himalayan shear zones: unravelling the timing of thrusting from structurally complex fault rocks. J. Geol. Soc., doi: https://doi.org/10.1144/ jgs2020-235.

Montemagni C., Carosi R., Fusi N., Iaccarino S., Montomoli C., Villa I.M. \& Zanchetta, S. (2020) - Three dimensional vorticity and time constrained evolution of the Main Central Thrus zone, Garhwal Himalaya (NW India). Terra Nova, https://doi. org/10.1111/ter.12450.

Montemagni C., Montomoli C., Iaccarino S., Carosi R., Jain A.K., Massonne H.-J. \& Villa I.M. (2019) - Dating protracted fault activities: microstructures, microchemistry and geochronology of the Vaikrita Thrust, Main Central Thrust zone, Garhwal Himalaya, NW India. Geol. Soc. London Spec. Publ., 481, 127-146.

Montomoli C., Iaccarino S., Carosi R., Langone A. \& Visonà D. (2013) - Tectonometamorphic discontinuities within the Greater Himalayan Sequence in Western Nepal (Central Himalaya): Insights on the exhumation of crystalline rocks. Tectonophysics, 608, 1349-1370.

Passchier C.W. (1987) - Stable position of rigid objects in noncoaxial flow: a study in vorticity analysis. J. Struct. Geol., 9, 679-690.

Schoene B. \& Bowring S.A. (2006) - U-Pb systematics of the McClure Mountain syenite: thermochronological constraints on the age of the ${ }^{40} \mathrm{Ar} /{ }^{39} \mathrm{Ar}$ standard MMhb. Contrib. Mineral. Petrol., 151, 615.

Searle M.P., Law R.D., Godin L., Larson K.P., Streule M.J., Cottle J.M. \& Jessup M.J. (2008) - Defining the Himalayan Main Central Thrust in Nepal. J. Geol. Soc., 165, 523-534.

Villa I.M., Hermann J., Müntener O. \& Trommsdorff V. (2000) - ${ }^{39} \mathrm{Ar}-$ ${ }^{40} \mathrm{Ar}$ dating of multiply zoned amphibole generations (Malenco, Italian Alps). Contrib. Mineral. Petrol., 140(3), 363-381.

Wallis S.R., Platt J.P. \& Knott S.D. (1993) - Recognition of synconvergence extension in accretionary wedges with examples from the Calabrian arc and the eastern Alps. Am. J. Sci., 293, 463495.

Weinberg R.F. (2016) - Himalayan leucogranites and migmatites: nature, timing and duration of anatexis, J. Metamorph. Geol. 34, 821-843.

Xypolias P., Spanos D., Chatzaras V., Kokkalas S. \& Koukouvelas I. (2010) - Vorticity of flow in ductile thrust zones: examples from the Attico-Cycladic Massif (Internal Hellenides, Greece). In: 
Continental Tectonics and Mountain Building: The Legacy of Peach and Horne (Law, R.D., Butler, R.W.H., Holdsworth, R.E., Krabbendam, M. and Strachan, R.A., eds). Geol. Soc. London Spec. Publ., 335, 687-714.
Zanchetta S., D’Adda P., Zanchi A., Barberini V. \& Villa I.M. (2011) - Cretaceous-Eocene compression in the central Southern Alps (N Italy) inferred from ${ }^{40} \mathrm{Ar} /{ }^{39} \mathrm{Ar}$ dating of pseudotachylytes along regional thrust faults. J. Geodyn., 51, 245-263. 